\title{
A model for acoustic absorbent materials derived from coconut fiber
}

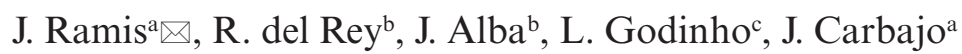 \\ a. Universidad de Alicante \\ b. Universitat Politècnica de València \\ c. CICC, University of Coimbra (Coimbra, Portugal) \\ \jramis@ua.es
}

\author{
Received 15 January 2013 \\ Accepted 25 April 2013 \\ Available on line 14 March 2014
}

\begin{abstract}
In the present paper, a methodology is proposed for obtaining empirical equations describing the sound absorption characteristics of an absorbing material obtained from natural fibers, specifically from coconut. The method, which was previously applied to other materials, requires performing measurements of airflow resistivity and of acoustic impedance for samples of the material under study. The equations that govern the acoustic behavior of the material are then derived by means of a least-squares fit of the acoustic impedance and of the propagation constant. These results can be useful since they allow the empirically obtained analytical equations to be easily incorporated in prediction and simulation models of acoustic systems for noise control that incorporate the studied materials.
\end{abstract}

KEYWORDS: Acoustic impedance; Absorption coefficient; Natural fibers; Empirical models

Citation / Citar como: Ramis, J.; del Rey, R.; Alba, J.; Godinho, L.; Carbajo, L. (2014). A model for acoustic absorbent materials derived from coconut fiber. Mater. Construcc. 64 [313], e008 http://dx.doi.org/10.3989/mc.2014.00513

RESUMEN: Un modelo para materiales absorbentes acústicos derivados de la fibra de coco. En este trabajo se describe el proceso seguido para obtener ecuaciones empíricas del comportamiento acústico de un material absorbente obtenido a partir de fibras naturales, concretamente el coco. El procedimiento, que ha sido ensayado con éxito en otros materiales, implica la realización de medidas de impedancia y resistencia al flujo de muestras del material bajo estudio. Las ecuaciones que gobiernan el comportamiento desde el punto de vista acústico del material se obtienen a partir del ajuste de ecuaciones de comportamiento de la impedancia acústica y la constante de propagación del material. Los resultados son útiles ya que, al disponer de ecuaciones analíticas obtenidas empíricamente, facilitan la incorporación de estos materiales en predicciones mediante métodos numéricos del comportamiento cuando son instalados formando parte de dispositivos para el control del ruido.

PALABRAS CLAVE: Impedancia acústica; Coeficiente de absorción; Fibras naturales; Modelos empíricos

Copyright: (C) 2014 CSIC. This is an open-access article distributed under the terms of the Creative Commons Attribution-Non Commercial (by-nc) Spain 3.0 License.

\section{INTRODUCTION}

In recent years, building regulations and the growing social demand for sustainability, have led to the emergence of new absorbent materials. For these new materials to be usable in the design stage, it becomes necessary to establish simplified models to easily incorporate them into simulation programs. This is one reason why, for a while now, various strategies have been proposed based on empirical models of material behavior or other linear equations. The materials studied in this respect have been the rock wool and glass wool, which are the most widely used in engineering practice. 
One of the most known and used models in this line is that of Delany and Bazley (1), which has established itself as a reference model in UNE_EN 12354:2004 standard (Part 6) (2) for fiber-based materials. These standards also cite Miki's later works $(3,4)$ models for foams, as well as Dunn and Davern (5) reference model in (2) for porous fibers, as well as models for textiles like those proposed by Garai and Pompoli (6). There are other empirical works, such as Wang et al. (7), based on a regression of different variables, or Shoshani and Yakubov (8) for finding maximum absorption. One should not forget the different empirical models proposed by Voronina (9-12), which make use of parameters such as the tortuosity factor or the structure associated with the distribution of the fibers or pores which characterize these materials.

In this work, a specific natural material is studied, namely coconut fiber. Coconuts, originated from the cocos nucifera variety of palms, can be harvested either from the ground (once they have fallen) or directly from the tree. After harvesting, the external fibrous layer of the fruit is separated from the hard shell in a so-called de-husking process, which can either be performed manually or mechanically. If green coconuts are harvested (after about six to twelve months on the tree), pliable white fibers may be extracted; a brown fiber may be obtained by harvesting fully mature coconuts. Each of these types of fibers is processed differently, and is used for different purposes. We here focus on the brown fibers, extracted from mature coconuts, and which are of interest to many technological and industrial applications. After extraction, the fibrous husks are soaked in pits or in nets in a slow moving body of water to swell and soften the fibers. Fibers are separated in two groups, namely longer (bristle) and shorter (mattress) fibers. After a cleaning and drying process, longer bristle fibers are then tied into bundles, while mattress fibers are compressed and packed into large bales.
These coconut fibers (known as coir) are abundant in many Asian countries such as India, SriLanka or Malaysia, and have been sometimes been regarded as a natural waste product. In recent years, sustainability concerns lead to an increasing interest in its application in construction, industrial and technological solutions, and raised the attention of both the industry and of the scientific community. Traditionally, these fibers were used in floor mats, doormats, brushes or mattresses; recently, technological industries, such as the automotive industry in Europe, have been increasingly using brown coir pads sprayed with rubber latex (bonding the fibers together) as upholstery padding. In the construction industry, its application has been studied in many forms, such as a reinforcing fiber in cement boards (see for example (13)), or as an insulation material (see, for example, (14)). In fact, physically, these fibers have appealing properties in what concerns their application in the construction industry. The high porosity and low density of those elements allows them to exhibit low thermal conductivity and good sound absorption coefficients (as illustrated by Fouladi et al. (15)), and thus makes them an interesting product.

Due to their natural unprocessed origin, coir fibers are typically heterogeneous both in color, thickness and length, and, as natural untreated materials, they also exhibit performance limitations in some respects. For example in what concerns fire reaction, these fibers are a combustible material, and so their application without protective measures becomes limited. Due to this behavior, commercial products incorporating a fireproof treatment became available for use when the mattresses are to be used with some possibility of being exposed to fire. Two forms of industrially produced coconut fiber mattresses can thus be commonly found in western countries, corresponding to semi-rigid mattresses (usually higher density panels) with fireproof treatment and to flexible
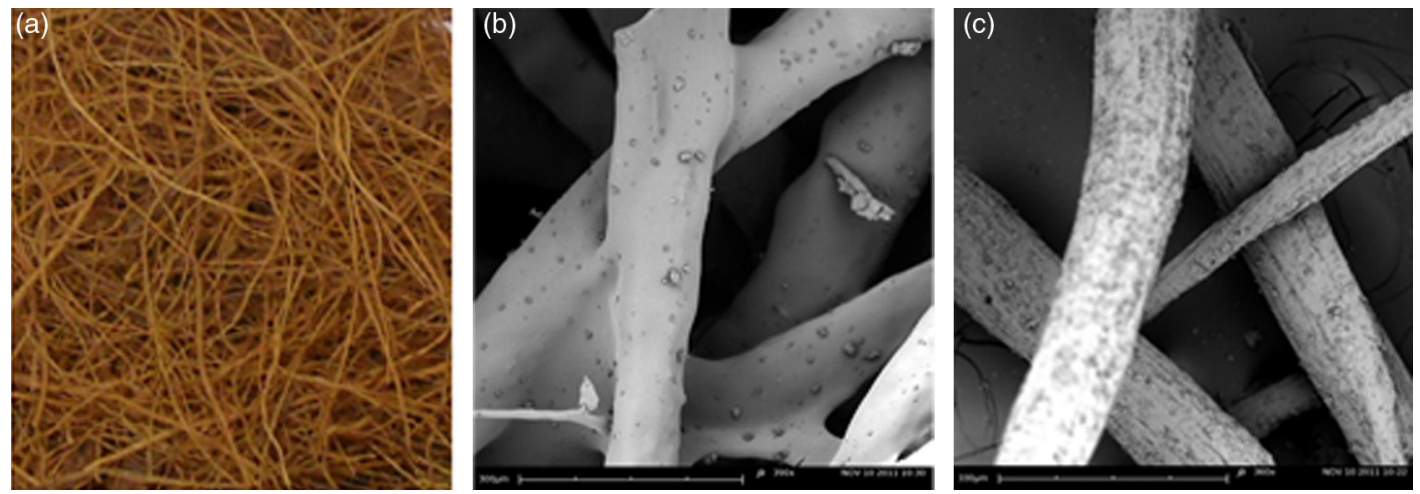

FIgURE 1. a) Detail of coconut fibers. b) Photograph of the fiber without fireproof treatment taken using an electron microscopic. c) Idem with fireproof treatment. 
mattresses (usually rolls with lower density), without any synthetic treatment.

Studies regarding its applicability from the acoustic viewpoint jobs include Fouladi et al. (15, 16), Nor et al. $(17,18)$ and Zulkifli et al. (19).

Figure 1 shows an image of absorbent material made from coconut fiber. As can be appreciated, this is a porous and fibrous. Thus, by their nature, are expected to play a similar role to other porous and fibrous materials such as rockwool.

This work has developed and implemented a method for obtaining an empirical model for the case of absorbent materials obtained from natural fibers, in particular coconut fiber, following a procedure similar to that described in $(20,21)$, inspired in (6).

\section{METHODOLOGY}

The model presented in this paper aims to predict the acoustic behavior of the fibrous material under study using the fewest number of non-intrinsic physical parameters, thus mitigating some propagation errors people make when using parameters obtained experimentally. Basically, it comes to finding the coefficients $C_{i}(\mathrm{i}=1 \ldots 8)$ that best fit the following equations for the case of the tested material (21).

$$
\begin{gathered}
\alpha=\left(\frac{2 \times \pi \times f}{c_{0}}\right) \times\left[C_{5} \times\left(\frac{\rho_{0} \times f}{r}\right)^{-c_{6}}\right] \\
\beta=\left(\frac{2 \times \pi \times f}{c_{0}}\right) \times\left[1+C_{7} \times\left(\frac{\rho_{0} \times f}{r}\right)^{-c_{8}}\right] \\
R=\rho_{0} \times c_{0}\left[1+C_{1} \times\left(\frac{\rho_{0} \times f}{r}\right)^{-c_{2}}\right] \\
X=-\rho_{0} \times c_{0}\left[C_{3} \times\left(\frac{\rho_{0} \times f}{r}\right)^{-c_{4}}\right]
\end{gathered}
$$

where $\alpha$ and $\beta$ are the real and imaginary parts of the propagation constant $\Gamma$ of the material, $R$ and $X$ are the real and imaginary parts of its characteristic impedance $Z, \sigma$ the air flow resistivity in Ns/m $\mathrm{m}^{4}, \rho_{0}$ is the air density, $f$ the frequency in $\mathrm{Hz}$ and $c_{0}$ the sound propagation velocity in air in $\mathrm{m} / \mathrm{s}$. The flow resistance $r$ of a sample of material can be obtained through multiplying the flow resistivity value by its thickness $e$.

To determine the specific acoustic impedance of a material, the commonly used transfer function method is used, which considers a plane-wave tube with a speaker mounted in one end. The sample of the material to be characterized is placed at the other end of the tube, at a distance $x_{1}$ from the microphone placed further away from the sample, and spaced a distance $s$ from the second microphone, as shown in Figure 2.

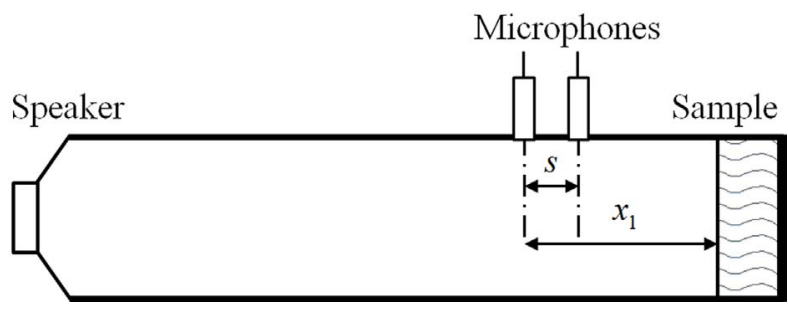

FIGURE 2. Experimental setup for measuring the impedance of a material using the method of the transfer function.

In the standards ASTM E1050 (22) and ISO 10534-2:1998 (23) or UNE EN ISO 10534-2:2002 (24), the measurement procedure is explained in detail, as well as its precision, limitations and sources of error or uncertainty.

Driving the speaker with a random noise signal (allowing an assessment of the full frequency range) and recording the sound pressures in the two microphone positions, these pressures can be written as the sum of the incident and reflected sound waves. The complex transfer function $H_{12}$ is then given by the relation between both pressures, and the reflexion coefficient can be obtained as:

$$
R=\frac{H_{12}-e^{-j k s}}{e^{j k s}-H_{12}} e^{j 2 k x_{1}}
$$

where $j=\sqrt{-1}$ and $k$ is the wave number in $\mathrm{rad} / \mathrm{m}$.

Thus, it is possible to obtain the specific acoustic impedance (real and imaginary) using the equation

$$
Z_{s}=Z_{0} \frac{1+R}{1-R}=Z_{\mathrm{R}}+j Z_{I}
$$

being $Z_{0}=\rho_{0} c_{0}$ the characteristic impedance of air and $Z_{R}$ and $Z_{1}$ the real and imaginary parts of specific acoustic impedance, that can also be obtained from the characteristic impedance of the material, its propagation constant and the sample thickness through:

$$
Z_{S}=\frac{Z}{Z_{0}} \operatorname{coth}(\Gamma e)
$$

From this reflexion coefficient, it becomes possible to compute an acoustic parameter of significant practical relevance, namely the sound absorption coefficient for normal incidence $\alpha_{n}$ as:

$$
\alpha_{n}=1-|R|^{2}
$$

This technique has the disadvantage of requiring the calculation of the transfer functions using successive measurements with exchanged measurement channels, in order to allow for phase correcting mismatches between microphones. Otherwise large errors can occur in the impedance calculation. 
The relation between this absorption coefficient for normal incidence and the acoustic impedance can be defined by the equation:

$$
\alpha_{n}=\frac{4 Z_{R} Z_{0}}{\left|Z_{s}\right|^{2}+2 Z_{0} Z_{R}+Z_{0}^{2}}
$$

where $Z_{0}=\rho_{0} c_{0}$.

To allow fitting the material model, it becomes necessary to obtain experimental data concerning the airflow resistance and absorption coefficient under normal incidence.

The following quadratic error function for the iterative method used here can be defined as:

$$
\varepsilon=\sum_{i=1}^{N}\left(\alpha_{n, i}-\hat{\alpha}_{n, i}\right)^{2}
$$

where $\alpha_{n, i}$ is the absorption coefficient for normal incidence, measured for the absorbing material under study, for the $i$-th frequency, and $\hat{\alpha}_{n, i}$ is the estimation of the that value obtained from application of equations [1] to [4]. To minimize the error function, the following expression must be set to zero:

$$
\frac{\partial \varepsilon}{\partial A_{i}}=2 \sum_{i=1}^{N}\left(\alpha_{n, i}-\hat{\alpha}_{n, i}\right) \frac{\partial \hat{\alpha}_{n, i}}{\partial A_{i}}=0 \quad i=1, \ldots, 8
$$

To obtain the coefficients that best describe the measured acoustic behavior of the samples, an iterative method of decrease of quadratic error function was used. As initial values (input values), different values proposed by different authors were tried, and all converged to the coefficients values as obtained and presented in this paper.

\section{RESULTS}

The experimental basis taken for adjusting the model consisted of:

a) Coconut fiber material without fireproof treatment with 2, 3 and $4 \mathrm{~cm}$ nominal thickness.

b) Idem with fireproof treatment 2 and $3 \mathrm{~cm}$.

As for the distribution of fiber diameter, its analysis was conducted on a sample including 200 random fibers, leading to an average fiber diameter of $0.25 \mathrm{~mm}$, with a size distribution between 1.17 and $0.48 \mathrm{~mm}$.

\subsection{Airflow resistance}

The experimental determination of the airflow resistance has been carried out according to the procedure specified in ISO $9053(25,26)$, using three
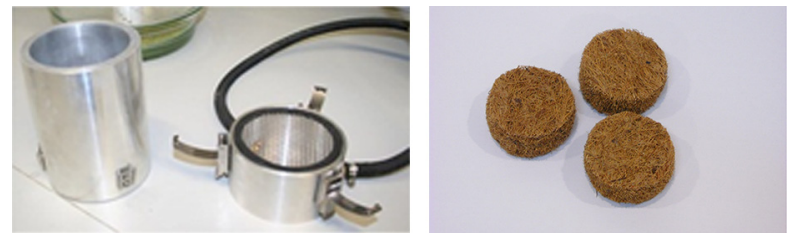

Figure 3. Left: Device used for measuring the flow resistance. Right: Samples prepared for the measurement.

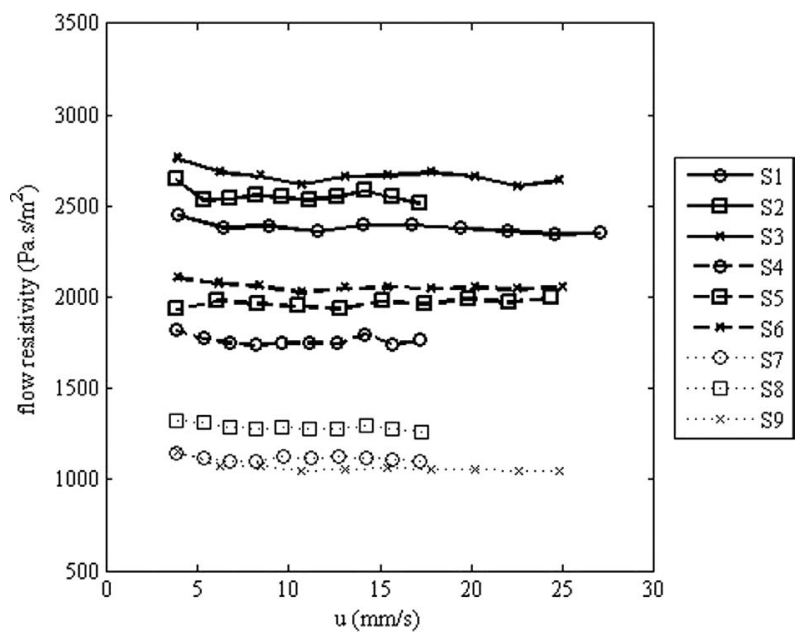

FigURE 4. Flow resistivity obtained for different air flow rates. $\mathrm{S} 1, \mathrm{~S} 2$ and $\mathrm{S} 3$ correspond to samples of coconut fiber without fireproof treatment $2 \mathrm{~cm}$ thick, S4, S5 and S6 correspond to samples of coconut fiber without fireproof treatment $3 \mathrm{~cm}$ thick, S7, S8 and S9 correspond to samples of coconut fiber without fireproof treatment $4 \mathrm{~cm}$ thick.

samples for each type of material. As suggested in the standard, for each of the samples ten measurements are performed for different air velocity $u$ in order to determine the airflow resistance. To obtain flow resistivity, it is only necessary to divide airflow resistance by the sample thickness. It is important to state that additional measurements have been carried out according to the method of Ingard and Dear (27), producing results of the same order of magnitude.

Figure 3 shows a detail of the measurement process and of the samples prepared for this purpose.

In order to illustrate the homogeneity of the results, Figures 4 and 5 show the results of the airflow resistivity for different air velocities (the flow can be calculated by multiplying by the tube's cross-section area).

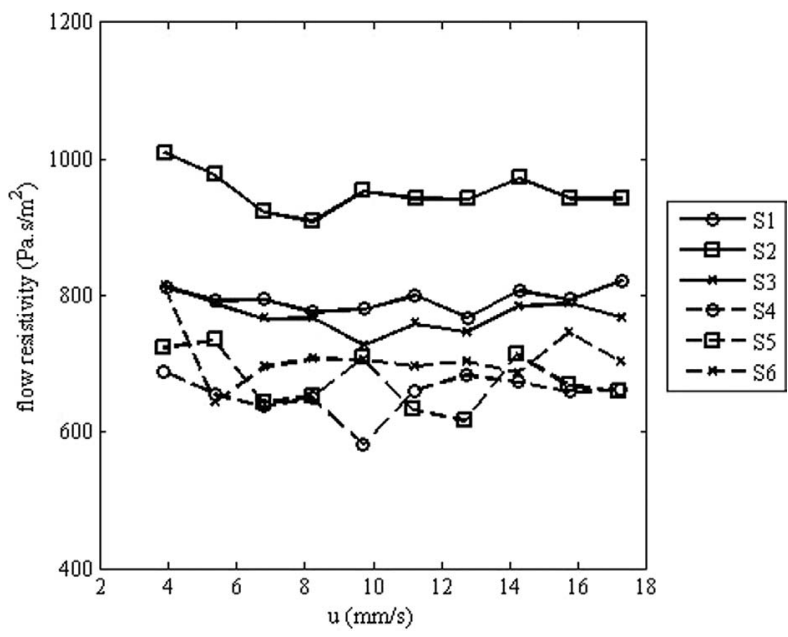

FiguRE 5. Flow resistivity obtained for different air flow rates using samples with fireproof treatment. S1, S2 and S3 correspond to samples $2 \mathrm{~cm}$ thick, and S4, S5 and $\mathrm{S} 6$ to samples $3 \mathrm{~cm}$ thick 
Figure 4 corresponds to samples of untreated coconut fiber (without flame retardant), S1, S2 and S3 correspond to samples $2 \mathrm{~cm}$ thick, S4, S5 and S6 are $3 \mathrm{~cm}$ thick and $\mathrm{S} 7, \mathrm{~S} 8$ and $\mathrm{S} 9$ are $4 \mathrm{~cm}$ thick.

Similarly, Figure 5 illustrates the case of samples with fireproof treatment, S1, S2 and S3 corresponding to samples of coconut fiber $2 \mathrm{~cm}$ thick, and S4, $\mathrm{S} 5$ and $\mathrm{S} 6$ to samples of coconut fiber $3 \mathrm{~cm}$ thick.

As already indicated above, for each of the 10 samples measurements are performed. The plotted results in Figures 4 and 5 reveal that the results do not exhibit a very significant variation, leading to almost horizontal lines for each tested sample. This behavior indicates a good stability of these tests.

As indicated in the reference standard, the value of the flow resistivity of each sample is the value at the origin of the horizontal axis of a linear law fitted to the performed measurements. The average values obtained from the three samples is the value taken as final. Here, the authors consider the uncertainty as the standard deviation of the tested samples. The results are shown in Tables 1 and 2 .

At this point, it is important to comment on the uncertainty associated with the measurement of the flow resistance. One of the most common problems in the treatment of absorbent materials in practice is that the sample thickness varies. In effect, all processes from manufacturing to final assembly, as well as the process for conducting measurements in an impedance tube or flow resistance, where the technician has to place the sample between racks and / or probes, the material is compressed. This compression with the resulting change in the thickness leads to greater uncertainty in predicting realistic values of flow resistance.

To complement this comment, one may perform the following mathematical reasoning. The following expression, from Bies and Hansen (28), relates the airflow resistivity, $\sigma$, with the density of the material, $\rho_{m}$, and the average fiber diameter, $d$ :

$$
\sigma=\frac{K_{2} \rho_{m}^{K_{1}}}{d^{2}}
$$

TABLE 1. Resistivity values obtained for samples 2,3 and $4 \mathrm{~cm}$ thick without fireproof treatment

\begin{tabular}{lc}
\hline $\begin{array}{l}\text { Coconut fiber without } \\
\text { fireproof treatment }\end{array}$ & Resistivity $\left(\boldsymbol{k P a} * \boldsymbol{s} / \boldsymbol{m}^{2}\right)$ \\
\hline $2 \mathrm{~cm}$ & $2.60 \pm 0.15$ \\
$3 \mathrm{~cm}$ & $1.94 \pm 0.15$ \\
$4 \mathrm{~cm}$ & $1.20 \pm 0.11$ \\
\hline
\end{tabular}

TABLE 2. Resistivity values obtained for samples 2 and $3 \mathrm{~cm}$ thick with fireproof treatment

\begin{tabular}{lc}
\hline $\begin{array}{l}\text { Coconut fiber with } \\
\text { fireproof treatment }\end{array}$ & Resistivity $\left(\boldsymbol{k P a} * \boldsymbol{s} / \boldsymbol{m}^{2}\right)$ \\
\hline $2 \mathrm{~cm}$ & $0.69 \pm 0.04$ \\
$3 \mathrm{~cm}$ & $0.85 \pm 0.11$ \\
\hline
\end{tabular}

$K_{1}$ and $K_{2}$ are characteristic parameters of each material.

On the other hand, if $C=\rho_{0} \times f / \sigma$, it is possible, applying Napieraian logarithms and considering increments, to state that:

$$
\frac{\Delta C}{C}=\frac{\Delta \sigma}{\sigma}
$$

This means that the relative variation in the normalized frequency $(C)$ is equal to the relative variation in the airflow resistivity.

Applying Napierian logarithms in [12], considering increments, and for a constant value of $d$, it is possible to write:

$$
\frac{\Delta \sigma}{\sigma}=K_{1} \times \frac{\Delta \rho_{m}}{\rho_{m}}
$$

As it can be seen in the literature, $K_{1}$ is always superior to one (8). Specifically, for the Garai and Pompoli (6) model, this value is $K_{1}=1.404$, and for the Bies and Hansen (28) model, $K_{1}=1.530$.

Analyzing [14], a 10\% change in the density of the material, leads to a relative variation in the flow resistivity higher than $15 \%$. In practice, the conditions of transport or mounting cause changes in material density above $30 \%$ - especially for low density rock wool $\left(30-40 \mathrm{~kg} / \mathrm{m}^{3}\right)$. This leads to relative variations in flow resistivity close to $50 \%$.

Therefore, it can be inferred that the uncertainty associated with the flow resistivity data is very large, and thus the presented data must be interpreted as a confidence interval.

\subsection{Absorption coefficient}

Figure 6 shows a detail of the measuring equipment used, particularly the end of the impedance tube with microphones and the sample placed at the end of the tube.

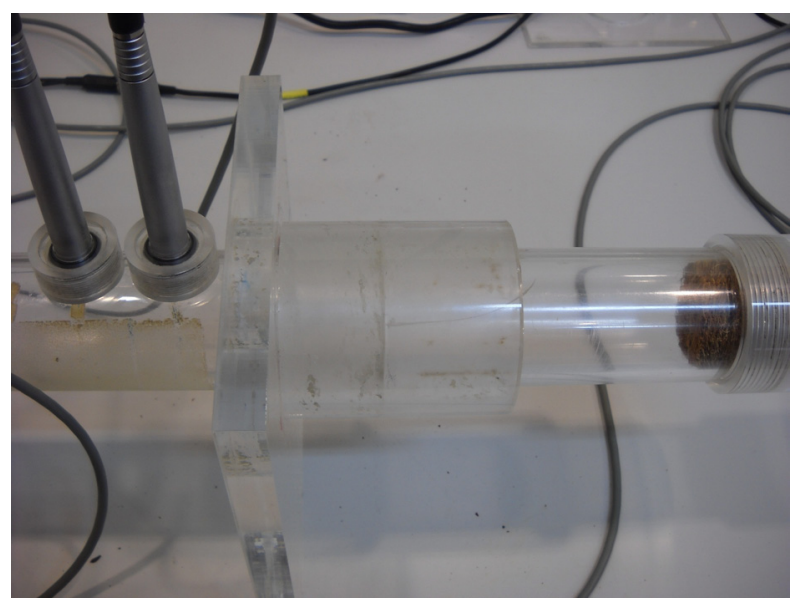

FIGURE 6. Detail of the measurement equipment used to determine the absorption coefficient, including a sample of coconut fiber. 
TABLE 3. Constants calculated for the implemented model

\begin{tabular}{lccccccc}
\hline $\mathbf{C}_{1}$ & $\mathbf{C}_{2}$ & $\mathbf{C}_{3}$ & $\mathbf{C}_{4}$ & $\mathbf{C}_{5}$ & $\mathbf{C}_{6}$ & $\mathbf{C}_{7}$ & $\mathbf{C}_{8}$ \\
\hline 0.0713 & -0.8749 & -0.1216 & -0.4520 & 0.2129 & -0.4857 & 0.0997 & -0.5988 \\
\hline
\end{tabular}

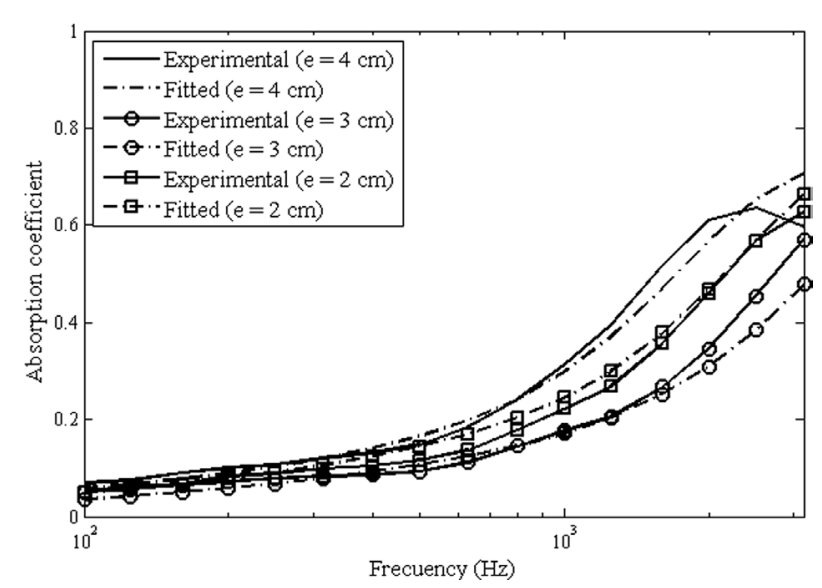

Figure 7. Absorption coefficient as a function of frequency for samples of untreated coir. Results of experimental measurements and adjustments (full line: experimental data, dashed: numerical setting) for samples 2,3 and $4 \mathrm{~cm}$ thick.

The following tables summarize the results of the experimental measurements and adjustments. To perform the measurements, the transfer function method has been applied $(23,24)$.

The adjustment is made without considering the extreme values at $100 \mathrm{~Hz}$ and $3150 \mathrm{~Hz}$. The corresponding constants are shown in Table 3.

Figures 7 and 8 compare the experimental results of the absorption coefficient at normal incidence with those empirically obtained from the coefficients shown in Table 3. Results are compared for untreated and treated (fireproof treatment) samples of coconut, respectively.

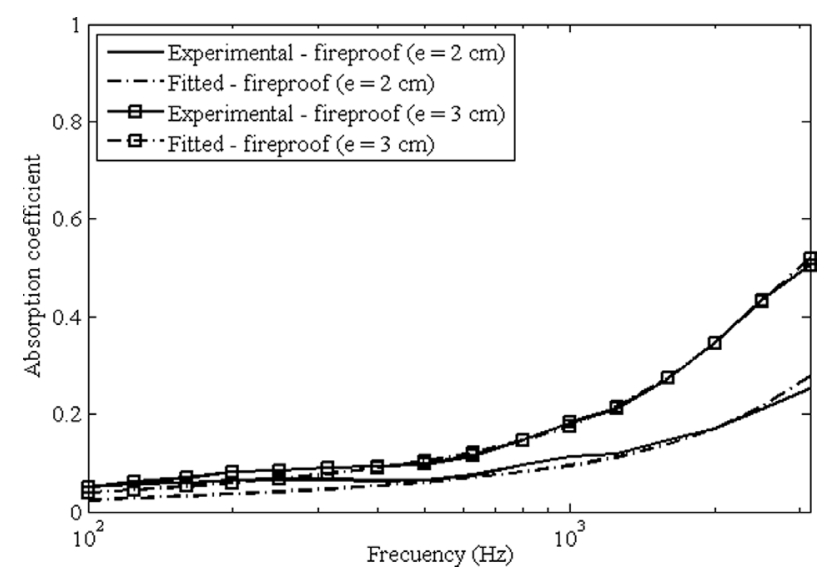

FIGURE 8. Absorption coefficient as a function of frequency for samples of treated (fireproof treatment) coir. Results of experimental measurements and adjustments (full line: experimental data, dashed: numerical setting) for samples 2 and $3 \mathrm{~cm}$ thick.

\section{CONCLUSIONS}

This paper described the process for obtaining empirical equations for the acoustic behavior of an absorbent material made natural fibers, particularly coconut fibers. The procedure, which has been successfully tested in other materials, involves performing impedance and airflow resistance measurements for samples of the material under study. The results are useful since the availability of empirically derived analytical equations, simplifies the incorporation of these materials into simulation programs in order to make predictions of their acoustic behavior when used as part of noise control devices. Note that there are different types of coconut fiber and, obviously, not all have the same degree of absorption.

\section{BIBLIOGRAPHY}

1. Delany, M.E.; Bazley, E.N. (1970) Acoustical Properties of Fibrous Absorbent Materials. Appl. Acoust. 3, 105-116. http://dx.doi.org/10.1016/0003-682X(70)90031-9.

2. UNE-EN 12354-6. (2004) Acústica en la edificación. "Estimación de las características de las edificaciones a partir de las características de sus elementos", parte 6, "Absorción sonora en espacios cerrados".

3. Miki, Y. (1990) Acoustical Properties of Porous MaterialsModifications of Delany-Bazley Models. J. Acoust. Soc. Jpn. (E) 11 [1], 19-24.

4. Miki, Y. (1990) Acoustical Properties of Porous MaterialsGeneralizations of empirical models. J. Acoust. Soc. Jpn. (E) 11 [1], 13-24.

5. Dunn, I.P.; Davern, W.A. (1986) Calculation of acoustic impedance of multi-layer absorbers. Appl. Acoust. 19, 321-334. http://dx.doi.org/10.1016/0003-682X(86)90044-7.

6. Garai, M.; Pompoli, F. (2005) A simple empirical model of polyester fibre materials for acoustical applications. Appl. Acoust. 66, 1383-1398. http://dx.doi.org/10.1016/j. apacoust.2005.04.008.

7. Wang, X.; Eisenbrey, J.; Zeitz, M.; Sun, J.Q. (2004) Multistage regression analysis of acoustical properties of polyurethane foams. J. Sound Vib. 273, 1109-1117. http:// dx.doi.org/10.1016/j.jsv.2003.09.039.

8. Shoshani, Y.; Yakubov, Y. (2000) Numerical assessment of maximal absorption coefficients for nonwoven fiberwebs. Appl. Acoust. 59, 77-87. http://dx.doi.org/10.1016/ S0003-682X(99)00015-8.

9. Voronina, N. (1996) Improved Empirical Model of Sound Propagation through a Fibrous Material. Appl. Acoust. 48 [2], 121-132. http://dx.doi.org/10.1016/0003-682X(95)00055-E.

10. Voronina, N. (1998) An Empirical Model for Elastic Porous Materials. Appl. Acoust. 55 [1], 67-83. http://dx.doi. org/10.1016/S0003-682X(97)00098-4.

11. Voronina, N. (1999) An empirical model for rigid-frame porous materials with low porosity. Appl. Acoust. 58, 295 304. http://dx.doi.org/10.1016/S0003-682X(98)00076-0.

12. Voronina, N.; Horoshenkov, K.V. (2003) A new empirical model for the acoustic properties of loose granular media. Appl. Acoust. 64, 415-432. http://dx.doi.org/10.1016/ S0003-682X(02)00105-6.

13. Asasutjarit, C.; Hirunlabh, J.; Khedari, J.; Charoenvai, S.; Zeghmati, B.; Cheul Shin, U. (2007) Development of coconut coir-based lightweight cement board. Constr. 
Build. Mater. 21 [2], 277-288. http://dx.doi.org/10.1016/j. conbuildmat.2005.08.028.

14. Panyakaew, S.; Fotios, S. (2011) New thermal insulation boards made from coconut husk and bagasse. Energ. Buildings. 43 [7], 1732-1739. http://dx.doi.org/10.1016/j. enbuild.2011.03.015.

15. Fouladi, M.H.; Nor, M.J.M.; Ayub, M.; Ali Leman, Z. (2010) Utilization of coir fiber in multilayer acoustic absorption panel. Appl. Acoust. 71 [3], 241-249. http:// dx.doi.org/10.1016/j.apacoust.2009.09.003.

16. Fouladi, M.H.; Ayub, M.; Nor, M.J.M. (2011) Analysis of coir fiber acoustical characteristics. Appl. Acoust. 72, 35-42. http://dx.doi.org/10.1016/j.apacoust.2010.09.007.

17. Nor, M.J.M.; Jamaludin, N.; Tamiri, F.M. (2004) A preliminary study of sound absorption using multi-layer coconut coir fibers. EJTA, 3-8.

18. Nor, M.J.M.; Ayub, M.; Zulkifli, R.; Amin, N.; Fouladi, M.H. (2010) Effect of different factors on the acoustic absorption of coir fiber. J. Applied Sci. 10 [22], 2887-2892. http://dx.doi.org/10.3923/jas.2010.2887.2892.

19. Zulkifli, R.; Nor, M.J.M.; Ismail, A.R.; Nuawi, M.Z.; Abdullah, S.; Tahir, M.F.M.; Rahman, M.N.A. (2009) Comparison of Acoustic Properties between Coir Fibre and Oil Palm Fibre. EJSR, 33 [1], 144-152.

20. del Rey, R.; Alba, J.; Sanchís, V. (2007) Proposal of an empirical model for absorbent acoustical materials based in kenaf. 19th International Congress on Acoustics (Madrid) 2-7 September 2007.

21. Ramis, J.; Alba, J.; del Rey, R.; Escuder, E.; Sanchís, V.J. (2010) Nuevos materiales absorbentes acústicos basados en fibra de kenaf. Mater. Construcc. 60 [299], 133-143. http:// dx.doi.org/10.3989/mc.2010.50809.

22. ASTME1050. (2010) Standard Test Method for Impedance and Absorption of Acoustical Material Using a Tube, Two Microphones and a Digital Frequency Analysis System.

23. UNE-EN ISO 10534-2 (1998) Acústica. "Determinación del coeficiente de absorción acústica y de la impedancia acústica en tubos de impedancia", parte 2, "Método de la función de transferencia".

24. ISO 10534-2. (2002) Acoustics - Determination of sound absorption coefficient and impedance in impedance tubes Part 2: Transfer-function method.

25. UNE-EN 29053. (1994) Acústica. Materiales para aplicaciones acústicas. Determinación de la resistencia al flujo de aire.

26. ISO 9053. (1991) Acoustics - Materials for acoustical applications. Determination of airflow resistance.

27. Ingard, K.U.; Dear, T.A. (1985) Measurement of Acoustic Flow Resistance. J. Sound Vib. 103, 567-572. http://dx.doi. org/10.1016/S0022-460X(85)80024-9.

28. Bies, D.A.; Hansen, C.H. (1980) Flow resistance information for acoustical design. Appl. Acoust. 13,357-391. http:// dx.doi.org/10.1016/0003-682X(80)90002-X 